\title{
Sleeve Gastrectomy as a Single-Stage Bariatric Operation: Indications and Limitations
}

\author{
Markos Daskalakis Rudolf A. Weiner \\ Center for Minimal-Invasive Surgery, Department of General and Bariatric Surgery, Krankenhaus Sachsenhausen, \\ Frankfurt/M., Germany
}

\section{Key Words}

Sleeve gastrectomy $\cdot$ Indications $\cdot$ Limitations $\cdot$ Review

\section{Summary}

Sleeve gastrectomy (SG) was initially described as a first-step procedure followed by either biliopancreatic diversion with duodenal switch or Roux-en-Y gastric bypass in super-superobese patients. Multiple recent reports have documented SG as single therapy in the treatment of morbid obesity. However, the indications for this procedure are still under evaluation. Accumulating data demonstrate that SG can be an effective and safe procedure for super-super-obese or high-risk patients either as a single operation or as a bridge to more definitive surgery. SG can also be performed in patients who require anti-inflammatory medication or in patients with conditions such as Crohn's disease, cirrhosis, anemia, or severe osteoporosis which preclude intestinal bypass. Furthermore, SG represents not only a safe alternative for morbidly obese patients on anticoagulant medication or immunosuppressive agents but also for those with multiple intra-abdominal adhesions or after failed gastric banding. In addition, SG can be performed safely in morbid obese adolescents. The main limitation of this novel bariatric procedure is the lack of longterm data on sustained weight loss and resolution of obesityrelated comorbidities. Moreover, the fact that SG is an irreversible operation adds to its weakness as a bariatric procedure, at least until definitive results concerning its efficacy are obtained. SG is effective and safe as a single-stage procedure for certain cohorts of patients. However, the broad application of $S G$ as a single-stage procedure in the bariatric field can be established only if the procedure is standardized and longterm results are available.

\section{Introduction}

Bariatric surgery is considered as the only effective treatment with long-term sustained results for morbid obesity $[1,2]$. Sleeve gastrectomy (SG) has been introduced as a multi-purpose bariatric operation [3]. SG was initially described as a first-step procedure followed by either biliopancreatic diversion with duodenal switch or Roux-en-Y gastric bypass in super-super-obese patients $\left(\mathrm{BMI}>60 \mathrm{~kg} / \mathrm{m}^{2}\right)$ or in high-risk patients $[4,5]$. Since SG proved to be effective, in short-term, in achieving considerable weight loss, it has been proposed by some to be used as a stand-alone bariatric procedure. Thus, SG has been indicated as a definitive treatment in patients with $\mathrm{BMI}>40 \mathrm{~kg} / \mathrm{m}^{2}$ or $\mathrm{BMI}>35 \mathrm{~kg} / \mathrm{m}^{2}$ when associated with comorbidities $[3,6,7]$. In this short review, we explore the role of $\mathrm{SG}$ as a single bariatric procedure, noting its indications but also its limitations.

\section{Surgical Technique}

As SG is a relatively new procedure, it is not included in current consensus guidelines. Since 2003, SG has been gaining in popularity, mainly in Europe. In Germany, during 2006 only 6 procedures were documented in the quality assurance study registry, whereas 127 isolated SG operations were recorded in 2007 [8].

Although SG can be performed by an open laparotomy, it is mostly performed through laparoscopy, which is the indicated approach. SG involves removing the fundus and greater curvature portion of the stomach, leaving only a lesser curvature tube [6]. The first step of the procedure is the dissection of the Hiss angle, defining the complete left crus of the diaphragm in order to facilitate the total resection of the fundus. The division of the vascular supply of the greater curvature of the stomach follows with the ligation of the gastrocolic and gastrosplenic ligaments close to the stomach, avoiding the gastroepiploic vessels. The third step of the procedure is the longitudinal transection of the stomach, which creates the

$\begin{array}{ll}\text { KARGER } & \text { ( 2009 S. Karger GmbH, Freiburg } \\ \begin{array}{ll}\text { Fax +497614520714 } \\ \begin{array}{l}\text { E-mail Information@Karger.de } \\ \text { www.karger.com }\end{array}\end{array} & \begin{array}{l}\text { Accessible online at: } \\ \text { www.karger.com/ofa }\end{array}\end{array}$

Prof. Dr. med. Rudolf A. Weiner

Chirurgische Klinik, Krankenhaus Sachsenhausen

Schulstraße 31, 60594 Frankfurt, Germany

Tel. +49 69 66 05-1131, Fax -1203

rweiner@khs-ffm.de 


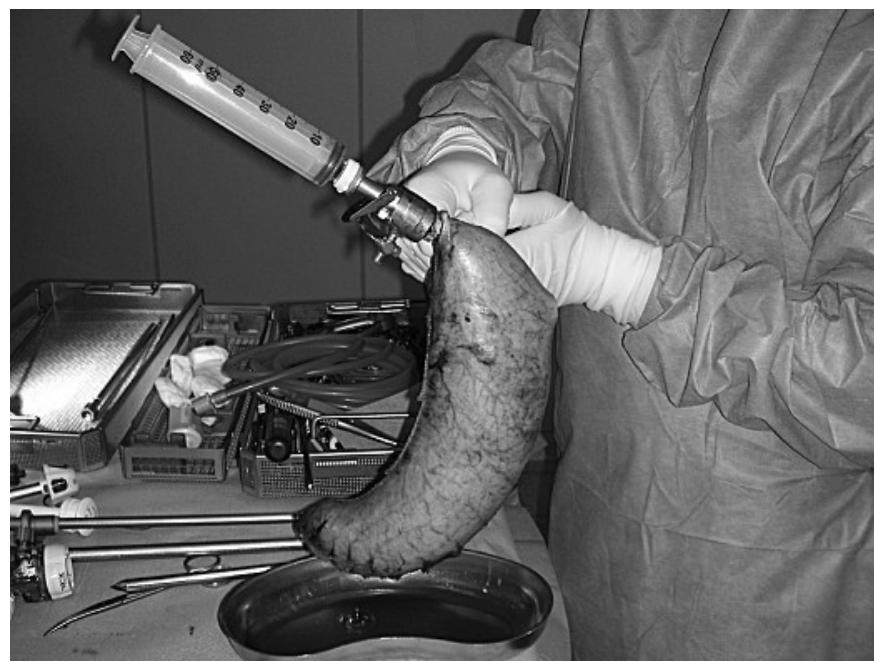

Fig. 1. Postoperative volume measurement of the resected part of the stomach.

'sleeve' stomach. A bougie is used to obtain a precise calibration and to avoid stenosis of the gastric remnant. There is no consensus in terms of where to start the gastrectomy and which bougie size to use. Nonetheless, a removed gastric volume of $<500 \mathrm{~cm}^{3}$ appears to be a predictor of treatment failure or early weight regain (fig. 1) [9].

The stomach is reduced without functional impairment. The pyloric preservation prevents dumping. Since no digestive anastomosis is involved, the whole digestive tract remains accessible to endoscopy and the risk of peptic ulcer is reduced. Moreover, no foreign material is used, as in the case of gastric banding, nor does SG alter the absorption of nutrients, vitamins, minerals, and drugs [10].

\section{Indications and Limitations}

Although classified as a restrictive procedure, SG appears to be more than just a gastric restrictive operation. Ghrelin, a potent orexigenic hormone, is mainly synthesized in the gastric fundus [11, 12]. With SG, almost the whole of the gastric fundus is surgically removed and the levels of ghrelin are significantly reduced [13]. Thus, SG is not only a multi-purpose operation but also a multifactorial one, with a restrictive aspect and a complex neurohormonal aspect not yet fully elucidated [14].

Patients experience excellent weight loss after SG alone, and multiple recent reports have documented SG as single therapy in the treatment of morbid obesity $[15,16]$. However, the indications for this procedure remain vague and are still under evaluation. Laparoscopic sleeve gastrectomy (LSG) can be offered in different groups of morbidly obese patients.

In super-super-obese patients, bariatric operations are more frequently related to technical difficulties due to bad exposure and an undersized operating field, caused by the excessive intra-abdominal fat deposition and ponderous fatty livers. SG represents an effective and safe procedure for these patients either as a single operation or as a bridge to more definitive surgery after significant

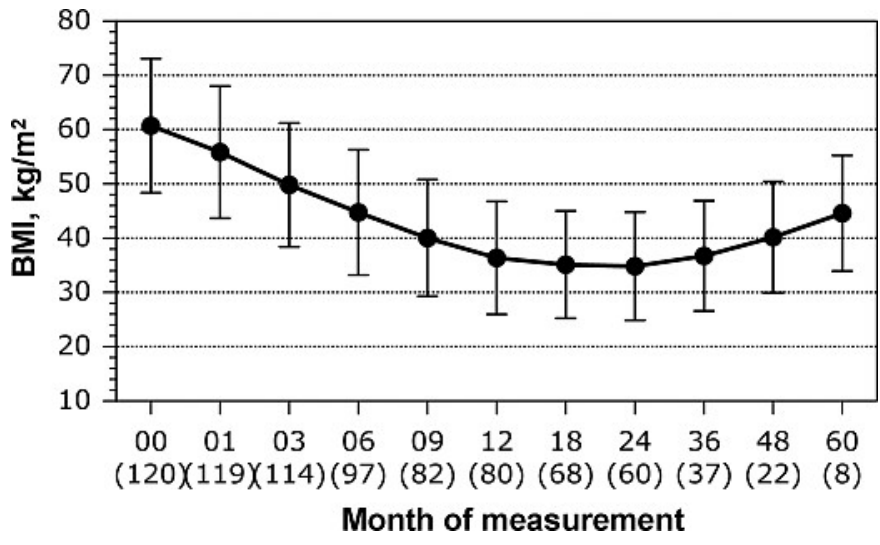

Fig. 2. Prospective (within 5 years) change of BMI after LSG for a total of 120 patients. The number of patients at every follow-up interval is shown in parenthesis. Total sample baseline: $\mathrm{n}=120$.

improvement of BMI and comorbidities [17]. Moreover, LSG can be beneficial for high-risk obese patients who require a short operation due to severe respiratory, cardiovascular disease, or advanced age $[18,19]$. LSG is associated with much less surgical intervention than laparoscopic gastric bypass; it can be done with relative technical ease and short operating time, and can thus minimize stress on such patients.

LSG can also be performed in patients requiring anti-inflammatory medication or in patients with conditions such as Crohn's disease, cirrhosis, anemia, or severe osteoporosis, which preclude intestinal bypass. Furthermore, LSG represents a safe alternative for morbidly obese with contraindications to malabsorptive operations, including patients on anticoagulant medication or immunosuppressive agents as well as adolescents [20]. In addition, LSG has been reported to be a safe and effective option for patients with multiple intra-abdominal adhesions, after extensive previous surgery, and for patients in need of rapid weight loss as a first step to a non-bariatric second procedure [7, 21]. Other indications for LSG as a primary procedure include morbidly obese patients in endemic regions (e.g. Japan, Chile) at risk of stomach cancer, where ongoing endoscopic surveillance is required [7]. SG has also been used effectively as a redo procedure in patients after failed gastric banding [22, 23]. Finally, recent reports demonstrated the shortterm efficacy of SG in the management of morbidly obese patients with type 2 diabetes mellitus and the metabolic syndrome [24].

'Durable' weight loss is one of the most important benefits of bariatric surgery, and it is a standard by which success or failure of weight-reducing procedures is measured. The main limitation of this novel bariatric procedure is the lack of long-term ( $>5$ years) data on sustained weight loss and resolution of obesity-related comorbidities. There is no clear evidence so far that weight loss obtained with LSG can be maintained in the long term. On the contrary, early results in small cohorts have demonstrated a regain of body weight at 5 years following LSG (fig. 2) [9]. Sleeve dilation is considered to be a major factor of long-term failure. However, there is no clear evidence that dilatation occurs after SG and, furthermore, there is no data demonstrating that dilatation is the 
main cause of failure as more complex mechanisms of gastric adaptation plus patients' eating habits seem to play a key role in the long-term efficacy of SG [25]. In the case of eventual regain of lost weight or insufficient weight loss, the surgeon must be ready to proceed to a second operation that must be part of his technical armamentarium.

The fact that SG is an irreversible bariatric operation highlights another major weakness of the procedure, at least until definitive results over its efficacy are obtained. Furthermore, SG has been reported to pose a risk of gastroesophageal reflux, perhaps because of alteration in the anatomy of the angle of Hiss [26]. Therefore, SG should be applied to morbidly obese patients with pre-existing gastroesophageal reflux disease in a cautious manner.

The LSG is not a 'simple' procedure. Although low, a mortality of approximately $1 \%$ has been reported, which in a high-volume center for LSG was increased to $3.2 \%$ for the group of high-risk patients $[3,27]$. Additionally, a median complication rate of $4.5 \%$ has recently been demonstrated after a collective analysis of 17 cohorts of patients receiving SG [27].

\section{Conclusion}

LSG is an effective and generally safe operation as a first-step procedure before gastric bypass or duodenal switch and as a singlestage procedure for certain cohorts of patients. Nonetheless, longterm studies are needed before LSG can be offered as a surgical option in the general bariatric field. Thus, it may be considered as stand-alone technique but further studies must establish a definitive standard of the procedure and also demonstrate its efficacy in the long term.

\section{Disclosure}

The authors declared no conflict of interest.

\section{References}

1 Buchwald H, Avidor Y, Braunwald E, Jensen MD, Pories W, Fahrbach K, Schoelles K: Bariatric surgery: a systematic review and meta-analysis. JAMA 2004;292:1724-1737.

\2 Sjöström L, Lindroos AK, Peltonen M, Torgerson J, Bouchard C, Carlsson B, Dahlgren S, Larsson B, Narbro K, Sjöström CD, Sullivan M, Wedel H, Swedish Obese Subjects Study Scientific Group: Lifestyle, diabetes, and cardiovascular risk factors 10 years after bariatric surgery. $\mathrm{N}$ Engl J Med 2004;351:2683-2693.

-3 Baltasar A, Serra C, Pérez N, Bou R, Bengochea M, Ferri L: Laparoscopic sleeve gastrectomy: a multi-purpose bariatric operation. Obes Surg 2005;15:1124-1128.

4 Regan JP, Inabnet WB, Gagner M, Pomp A: Early experience with two-stage laparoscopic Roux-en$\mathrm{Y}$ gastric bypass as an alternative in the supersuper obese patient. Obes Surg 2003;13:861-864.

5 Almogy G, Crookes PF, Anthone GJ: Longitudinal gastrectomy as a treatment for the high-risk super-obese patient. Obes Surg 2004;14:492-497.

6 Deitel M, Crosby RD, Gagner M: The First International Consensus Summit for Sleeve Gastrectomy (SG), New York City, October 25-27, 2007. Obes Surg 2008;18:487-496.

7 Tucker ON, Szomstein S, Rosenthal RJ: Indications for sleeve gastrectomy as a primary procedure for weight loss in the morbidly obese. J Gastrointest Surg 2008;12:662-667.

8 Stroh C, Birk D, Flade-Kuthe R, Frenken M, Herbig B, Höhne S, Köhler H, Lange V, Ludwig K, Matkowitz R, Meyer G, Meyer F, Pick P, Horbach T, Krause S, Schäfer L, Schlensak M, Shang E, Sonnenberg T, Susewind M, Voigt H, Weiner R, Wolff S, Lippert H, Wolf AM, Schmidt U, Manger T, Bariatric Surgery Working Group: A nationwide survey on bariatric surgery in Germany - results 2005-2007. Obes Surg 2008;DOI: 10.1007/s11695-008-9736-z.

$\checkmark 9$ Weiner RA, Weiner S, Pomhoff I, Jacobi C, Makarewicz W, Weigand G: Laparoscopic sleeve gastrectomy - influence of sleeve size and resected gastric volume. Obes Surg 2007;17:1297-1305.
10 Iannelli A, Dainese R, Piche T, Facchiano E, Gugenheim J: Laparoscopic sleeve gastrectomy for morbid obesity. World J Gastroenterol 2008;14: 821-827.

11 Kojima M, Hosoda H, Date Y, Nakazato M, Matsuo H, Kangawa K: Ghrelin is a growth-hormone-releasing acylated peptide from stomach. Nature 1999;402:656-660.

12 Lee HM, Wang G, Englander EW, Kojima M, Greeley GH Jr: Ghrelin, a new gastrointestinal endocrine peptide that stimulates insulin secretion: enteric distribution, ontogeny, influence of endocrine and dietary manipulations. Endocrinology 2002;143:185-190.

13 Langer FB, Reza Hoda MA, Bohdjalian A, Felberbauer FX, Zacherl J, Wenzl E, Schindler K, Luger A, Ludvik B, Prager G: Sleeve gastrectomy and gastric banding: effects on plasma ghrelin levels. Obes Surg 2005;15:1024-1029.

14 Melissas J, Daskalakis M, Koukouraki S, Askoxylakis I, Metaxari M, Dimitriadis E, Stathaki M, Papadakis JA: Sleeve gastrectomy - a 'food limiting' operation. Obes Surg 2008;18:1251-1256.

15 Felberbauer FX, Langer F, Shakeri-Manesch S, Schmaldienst E, Kees M, Kriwanek S, Prager M, Prager G: Laparoscopic sleeve gastrectomy as an isolated bariatric procedure: intermediate-term results from a large series in three Austrian centers. Obes Surg 2008;18:814-818.

16 Nocca D, Krawczykowsky D, Bomans B, Noël P, Picot MC, Blanc PM, de Seguin de Hons C, Millat B, Gagner M, Monnier L, Fabre JM: A prospective multicenter study of 163 sleeve gastrectomies: results at 1 and 2 years. Obes Surg 2008; 18:560-565.

17 Gagner M, Gumbs AA, Milone L, Yung E, Goldenberg L, Pomp A: Laparoscopic sleeve gastrectomy for the super-super-obese (body mass index $>60 \mathrm{~kg} / \mathrm{m}^{2}$ ). Surg Today 2008;38:399-403.

18 Mognol P, Chosidow D, Marmuse JP: Laparoscopic sleeve gastrectomy as an initial bariatric operation for high-risk patients: initial results in 10 patients. Obes Surg 2005;15:1030-1033.
19 Cottam D, Qureshi FG, Mattar SG, Sharma S, Holover S, Bonanomi G, Ramanathan R, Schauer P: Laparoscopic sleeve gastrectomy as an initial weight-loss procedure for high-risk patients with morbid obesity. Surg Endosc 2006;20:859-863.

20 Till H, Blüher S, Hirsch W, Kiess W: Efficacy of laparoscopic sleeve gastrectomy (LSG) as a stand-alone technique for children with morbid obesity. Obes Surg 2008;18:1047-1049.

21 Quesada BM, Roff HE, Kohan G, Salvador Oría A, Chiappetta Porras LT: Laparoscopic sleeve gastrectomy as an alternative to gastric bypass in patients with multiple intraabdominal adhesions. Obes Surg 2008;18:566-568.

22 Bernante P, Foletto M, Busetto L, Pomerri F, Pesenti FF, Pelizzo MR, Nitti D: Feasibility of laparoscopic sleeve gastrectomy as a revision procedure for prior laparoscopic gastric banding. Obes Surg 2006;16:1327-1330.

23 Gagner M, Gumbs AA: Gastric banding: conversion to sleeve, bypass or DS. Surg Endosc 2007;21:1931-1935.

24 Vidal J, Ibarzabal A, Romero F, Delgado S, Momblán D, Flores L, Lacy A: Type 2 diabetes mellitus and the metabolic syndrome following sleeve gastrectomy in severely obese subjects. Obes Surg 2008;18:1077-1082.

-25 Langer FB, Bohdjalian A, Felberbauer FX, Fleischmann E, Reza Hoda MA, Ludvik B, Zacherl J, Jakesz R, Prager G: Does gastric dilatation limit the success of sleeve gastrectomy as a sole operation for morbid obesity? Obes Surg 2006;16:166-171.

26 Himpens J, Dapri G, Cadière GB: A prospective randomized study between laparoscopic gastric banding and laparoscopic isolated sleeve gastrectomy: results after 1 and 3 years. Obes Surg 2006;16:1450-1456.

27 Frezza EE, Reddy S, Gee LL, Wachtel MS: Complications after sleeve gastrectomy for morbid obesity. Obes Surg 2008;DOI: 10.1007/s11695008-9677-6. 